Lingüística

Vol. 36-2, diciembre 2020: 71-87

ISSN 2079-312X en línea

DOI: $10.5935 / 2079-312 X .20200015$

\title{
REDEFINIENDO CATEGORÍAS: FORMAS SUBJETIVAS E INTERSUBJETIVAS EN EL TOBA HABLADO EN EL ESTE DE LA PROVINCIA DE FORMOSA (ARGENTINA)
}

\author{
CATEGORIAS REDEFINIDAS: FORMAS SUBJETIVAS E INTERSUBJETIVAS NO \\ TOBA FALADO NA REGIÃO LESTE DA PROVÍNCIA DE FORMOSA (ARGENTINA)
}

\section{REDEFINING CATEGORIES: SUBJECTIVE AND INTERSUBJECTIVE FORMS IN THE TOBA LANGUAGE SPOKEN IN EASTERN FORMOSA PROVINCE} (ARGENTINA)

\author{
Raúl Eduardo González \\ Universidad Nacional del Nordeste, Argentina \\ raul_eduardogonzalez@yahoo.com.ar \\ 0000-0002-1495-8434
}

\section{Resumen}

El objetivo de este trabajo es retomar un análisis esbozado en González (2015), respecto a la dificultad para distinguir entre pronombres demostrativos y personales en la tercera persona en el toba hablado en el este de Formosa. Siguiendo a Cysouw (1997), proponemos nuevas categorías teóricas que nos permiten explicar desde criterios translingüísticos más amplios el funcionamiento de las unidades lingüísticas que presentamos como "pronombres personales" y "pronombres demostrativos". Discutimos si existe la tercera persona como categoría en toba y los criterios sobre los cuales identificamos los distintos paradigmas pronominales. Proponemos la distinción entre formas subjetivas e intersubjetivas. El corpus analizado fue recolectado en sucesivos trabajos de campo en comunidades tobas del este de Formosa y se compone de 5 horas de texto libre narrativo y alrededor de 200 cláusulas elicitadas con consultante de referencia. El mismo fue analizado a partir del método de la conmutación de morfemas y de cláusulas.

Palabras clave: pronombres; demostrativos; deixis; subjetivo; intersubjetivo.

\section{Resumo}

O objetivo deste trabalho é voltar a uma análise delineada em González (2015), a respeito da dificuldade de distinguir entre pronomes demonstrativos e pessoais na terceira pessoa no toba falado em Formosa oriental. 
Seguindo Cysouw (1997), propomos novas categorias teóricas que permitem explicar a partir de critérios translinguísticos mais amplos o funcionamento das unidades linguísticas que apresentamos como "pronomes pessoais" e "pronomes demonstrativos". Discutimos se a terceira pessoa existe como uma categoria em toba e os critérios pelos quais identificamos os diferentes paradigmas pronominais. Propomos a distinção entre formas subjetivas e intersubjetivas. O corpus analisado foi coletado em sucessivos estudos de campo nas comunidades toba no leste de Formosa e é composto por cinco horas de texto narrativo livre e cerca de 200 orações eliciadas com um consultor de referência. Foi analisado a partir do método de comutação de morfemas e orações.

Palavras-chave: pronomes; demonstrativo; deixis; subjetivo; intersubjetivo.

\begin{abstract}
The aim of this paper is to propose a possible better way to categorize referential elements outlined in González (2015). The distinction between 3rd Personal Pronouns and Demonstratives is not so clear in toba.

We follow the proposal of Cysouw (1997) and we postulate new theoretical categories from a cross-linguistic point of view. We discuss whether the third person exists as a category in toba and the criteria on which we identify the different pronominal paradigms. We propose an opposition between subjective elements and intersubjective elements. This research is based on a corpus composed of five hours of oral narrative texts and two hundred elicited clauses collected in fieldwork carried out in Toba communities from eastern Formosa (Argentina). The conmutation of morphemes and clauses was the main method used to analyze the linguistic data.
\end{abstract}

Key Words: pronouns; demonstratives; deixis; subjective; intersubjective.

Recibido: 03/01/2019

Aceptado: $01 / 05 / 2019$

\title{
1. Introducción
}

\subsection{El pueblo toba de Formosa y su lengua}

El toba es una lengua que pertenece a la familia guaycurú, junto al pilagá, mocoví, caduveo y las ya extintas abipón y mbayá (Tovar y Larrucea de Tovar 1984: 43). En la región del Gran Chaco argentino $^{1}$ es hablada principalmente en las provincias de Chaco, Formosa y, en menor proporción, en el este de

\footnotetext{
1 La llamada región del Gran Chaco incluye a los países de Argentina, Paraguay, Brasil y Bolivia; limita al oeste con la precordillera de los Andes, al sur con la cuenca del río Salado, al este con los ríos Paraguay y Paraná y al norte con la meseta del Mato Grosso (Miller 1979: 26).
} 
Salta. A partir de procesos migratorios internos existen actualmente importantes enclaves en la ciudad de Rosario (provincia de Santa Fe), La Plata (provincia de Buenos Aires) y en el conurbano bonaerense. Según los datos del último censo (INDEC 2012) la población estimada a nivel nacional es de 126.967 personas que se autoadscriben como tobas. Hasta fines del siglo XIX estaban organizados en grupos cazadores-recolectores nómades que migraban estacionalmente a través de la región chaqueña (noreste de Argentina, centrosur de Paraguay, y sudeste de Bolivia). Con la ocupación de sus territorios por fuerzas militares argentinas entre 1884 y 1912, y la colonización subsiguiente, los tobas fueron violentamente forzados a instalarse en forma sedentaria y a trabajar en obrajes madereros, en la agricultura y la ganadería e ingenios azucareros.

En la provincia de Formosa, se ubican principalmente en el sureste (Dpto. Pilcomayo, Formosa capital, Dpto. Laishí) y también en el centro (Departamentos Pilagá, Pirané y Patiño) donde habitan mayoritariamente grupos pilagá. Los llamados tobas del oeste se ubican en el noroeste de Formosa, en los Departamentos Matacos y Bermejo (Fabre 2009: 81-86; Wright 2002: 62-63).

\subsection{Tobas del este y tobas del oeste de Formosa}

En Formosa, las principales diferencias etnohistóricas entre los tobas orientales y los llamados tobas occidentales, tobas del oeste o ñachilamole'k, radican en los grupos indígenas con los que entablaron relaciones de alianza o guerra y en la naturaleza del contacto con la población criolla. Los tobas del este fueron enemigos de grupos maká, que habitaban la franja derecha del Río Pilcomayo en el Chaco paraguayo, así como también se consideraban enemigos de sus vecinos pilagás. Los tobas del oeste, por el contrario, fueron aliados de los pilagás, estableciendo matrimonios interétnicos e intercambios económicos de diverso tipo, además de establecer relaciones con otros grupos tobas hacia el norte de su territorio en lo que actualmente es Bolivia.

Asímismo, los territorios orientales de la provincia de Formosa fueron objeto de exploración e intentos de ocupación por parte de los españoles ya desde los siglos XVII y XVIII por medio de diversas estrategias como ser: ocupación militar, fundación de pequeñas ciudades agrícolas y establecimiento de misiones jesuíticas. Estos intentos fueron ineficaces por la aguerrida defensa que los grupos tobas hicieron de su territorio. El oeste de la provincia, en cambio, permaneció durante mucho tiempo inexplorado y fuera de los circuitos económicos hasta mediados del siglo XX (Mendoza y Wright 1989: 245).

Ambos grupos hablan variedades lingüísticas ininteligibles entre sí, mientras que los tobas del este, por su parte, declaran que pueden entenderse con los hablantes de la provincia de Chaco, si bien perciben diferencias entre las distintas formas de habla en ambas provincias (Carpio 2012; González 2015, V. Figura 1). 


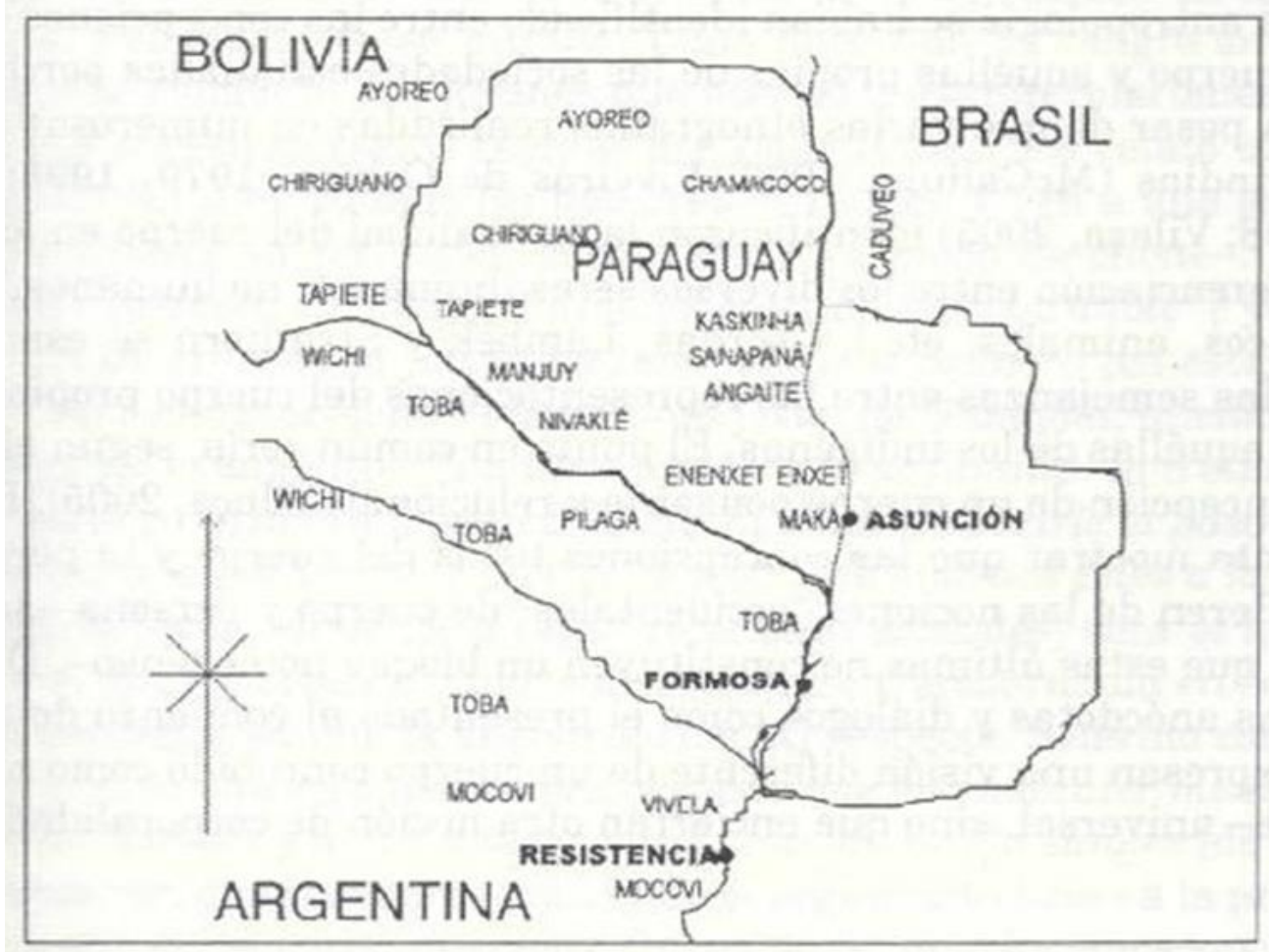

Figura 1: Localización geográfica de los tobas de Formosa (Tola 2008: 61)

\subsection{Rasgos tipológicos generales}

Más allá de la existencia de distintas variedades de la lengua, una de ellas ininteligible con las restantes, es factible enumerar algunos rasgos que les son comunes en términos tipológicos. Se trata de una lengua que no posee adjetivos, marcación de caso ni adposiciones; presenta tendencia a la polisíntesis, oposición verbo/nombre y marcación de núcleo en lo que respecta a la relación entre predicado y argumentos. En cuanto al orden de los constituyentes, las combinaciones más utilizadas son: VS, AVP -cuando $P$ se codifica por medio de frase nominal- y PVA -cuando $P$ se expresa pronominalmente. Los índices pronominales en los verbos presentan alineación escindida de acuerdo a la jerarquía de persona.

En la tercera persona se observa un patrón de alineación tripartito, según el cual $\mathrm{S}, \mathrm{A}$ y $\mathrm{P}$ son tratados de manera diferente mientras que para los participantes en el acto de habla predomina un sistema nominativo-acusativo. La lengua cuenta, además, con un variado número de afijos verbales que codifican espacio y dirección, algunos de ellos se comportan como aplicativos. Los verbos carecen de expresión morfológica de tiempo, solamente la categoría de aspecto es codificada por medio de afijos verbales (Carpio 2007, 2012; Censabella 2002, 2007; González 2010, 2015).

\section{Metodología}

El trabajo de campo se llevó a cabo en dos comunidades del oriente de la provincia de Formosa: 
(i) Nam Qom, barrio periurbano situado a 11 kilómetros de la ciudad de Formosa: concentra un gran número de familias originarias (3.500 personas aproximadamente) de distintas regiones del Chaco argentino.

(ii) Excolonia secular Bartolomé de las Casas: de acuerdo con Wright (2008: 105), fue fundada en 1911, mismo año que la colonia Napalpí en la provincia de Chaco. La comunidad está ubicada a 8 kilómetros de la ciudad de Comandante Fontana (Departamento Patiño), en el centro-este de la provincia.

Es un enclave semi-rural con alrededor de 3.000 habitantes y reúne, además de los nativos del lugar, a hablantes provenientes de diversos puntos, como Tacaaglé - sureste provincial- o Ibarreta -más hacia el centro de la Provincia. En el mapa 1 se observa la localización de los grupos tobas en la región del Gran Chaco.

En todos los casos hemos trabajado con hablantes bilingües tobacastellano, que poseen la lengua indígena como primera lengua. En total, el corpus que analizamos para este trabajo asciende a 5 horas de texto libre oral de carácter narrativo, registrado con hablantes adultos mayores de 50 años y ancianos. Los textos fueron traducidos con consultante de referencia y segmentados morfema a morfema.

Estos relatos orales (historias de vida, relatos históricos, comentarios, etc.) han sido obtenidos a pedido del investigador o bien inducidos a partir de un estímulo audiovisual que actúa como disparador para el hablante. Todo el material fue registrado mediante grabadoras digitales de voz. Al tratarse de una lengua no-estandarizada en proceso de desplazamiento, en la selección de los consultantes fue necesario considerar aspectos fundamentales de la historia sociolingüística de los mismos y diversas variables como lugar de residencia (ámbito urbano o rural) y nivel de escolaridad alcanzado en la lengua dominante.

En cuanto al análisis del corpus, la estrategia metodológica de base consiste en aislar oraciones simples, las cuales representan el punto de partida en la comparación de otras estructuras oracionales. El método nuclear es el de la conmutación de morfemas y cláusulas, lo que nos permite reconocer y clasificar los morfemas y agruparlos en paradigmas, así como establecer sus reglas de combinación en la cadena sintagmática. Se trata de una metodología que implica una estrecha correlación entre forma y función, lo cual constituye la piedra angular de la tipología funcional cuyo enfoque adoptamos a lo largo de este trabajo.

\section{Discusión teórica}

En este apartado introducimos las categorías y conceptos claves que deseamos poner en discusión, en la búsqueda de herramientas teóricas que nos permitan análisis translingüísticos más abarcativos. No debemos asumir como aprioris conceptualizaciones o esquemas que se adaptan a los patrones de lenguas indoeuropeas, con mayor tradición descriptiva, pero que no son pertinentes para analizar otras lenguas, como la que presentamos en este trabajo. 


\subsection{El pronombre como categoría lingüística}

Para Siewierska (2004: 5-6), la oposición entre primera y segunda personas versus tercera suele manifestarse en la inexistencia de formas pronominales para la expresión de esta última en algunas lenguas del mundo. De acuerdo con su propuesta, en dichas lenguas se recurre a una forma deíctica o pronombre demostrativo que "ocupa el lugar" de los pronombres de tercera persona, o bien se utilizan directamente expresiones léxicas. Se trata, a nuestro entender, de un argumento circular, que presupone la necesidad de dar cuenta de la existencia de la tercera persona o de una estrategia equivalente. Es decir, aunque en abstracto, la existencia de la tercera persona es un a priori que condiciona el análisis de los datos. Más allá de esto, la categoría pronombre como tal ha sido y es discutida teóricamente como categoría válida translingüísticamente. Los criterios más frecuentes para definir un "pronombre" son:

(i) Función anafórica

(ii) Concordancia con otros elementos como artículos o determinantes y con morfemas verbales

(iii) Oposición Pronombre/nombre

Retomando el trabajo de Siewierska (2004: 10), antes que una oposición discreta, existe más bien a un continuum de oposición nombre-pronombre según la lengua que se considere. De manera escalar, los considerados pronombres pueden tener características pronominales más prototípicas o bien ubicarse más cerca de los nombres y frases nominales, en cuanto a los siguientes rasgos:

- Clase sintáctica cerrada/abierta

- Opacidad/transparencia morfológica

- Escaso contenido semántico

- Bajo contenido sociolingüístico

- Codificación de la persona gramatical

- Imposibilidad de tomar modificadores

- Restricciones en cuanto al contenido referencial

+ Nominal

+ Pronominal

De acuerdo con Cysouw (1997) el valor anafórico solamente es puesto en discusión para la tercera persona, ya que en el caso de la primera y la segunda se trata de elementos netamente deícticos que refieren a las personas presentes en el acto de habla.

La oposición entre anáfora/deixis se da entre formas de tercera persona o pronombres demostrativos, es decir, elementos distintos a las formas de primera y segunda persona. En ejemplos como (1) puede observarse el uso anafórico de "él":

(1) El niño se cayó de la bicicleta. Él estaba sufriendo mucho dolor 
Las formas puramente anafóricas, sin embargo, no existen, dado que también pueden ser utilizadas de manera deíctica como en (2):

(2) ¿Quién es el niño que se ha caído de la bicicleta? É (apuntándolo)

Lo mismo ocurre, en castellano, con los llamados pronombres demostrativos, que si bien poseen un uso básicamente deíctico, también se utilizan anafóricamente, como se muestra en (3a-b).

(3) a. El hombre calvo estaba parado en la puerta. Este fue quien me detuvo al querer entrar.

b. Este (apuntándolo, grado de distancia próximo) fue quien me salvó.

De este modo, la oposición entre anáfora pura/deixis, para distinguir entre pronombres personales de tercera persona y demostrativos, no implica concebir categorías con límites rígidos entre sí, sino más bien con limites difusos.

\subsection{Sobre la universalidad de la tercera persona}

De acuerdo con Cysouw (1997: 1), la categoría "pronombre de tercera persona" es útil para explicar, por ejemplo, el sistema pronominal del inglés y otras lenguas indoeuropeas. No obstante, no se trata de una categoría válida para otras lenguas del mundo, en las que no existe oposición entre pronombres personales de tercera persona y pronombres demostrativos. Todas las lenguas del mundo poseen elementos que permiten codificar la primera persona (hablante) y a la segunda (oyente), mientras que el caso de la tercera persona no parece ser universal sino, al contrario, problemática. Una forma frecuente de caracterizar a la tercera es como "no participante en el acto de habla", o bien como la "no persona".

Esta caracterización negativa se vuelve, incluso, más problemática cuando se consideran lenguas que tienen más de tres personas, una cuarta, mejor denominada sistema de primera persona plural inclusivo/exclusivo. Cuando las formas demostrativas cumplen funciones anafóricas, al estilo de pronombres de tercera persona, tiende a decirse también que la tercera persona tiene codificación "cero" o nula".

En todos los casos, partimos siempre de una especie de corsé o chaleco de fuerza, en el cual la preexistencia de la tercera persona está dada de antemano.

Nuestra propuesta, en línea con Cysouw (1997), es que la tercera persona no es una categoría universal e, incluso, resulta problemática a la hora de pensar en perspectivas teóricas translingüísticas. No ocurre lo mismo con la primera y la segunda, las cuales pueden hallarse en cualquier lengua. Como mostraremos en nuestros datos de la lengua toba, resulta necesario diluir la categoría "tercera persona" y redefinir las unidades deícticas en torno a distinciones más amplias en términos translingüísticos. 


\section{Pronombres demostrativos en toba}

Como ya ha sido descrito para otras variedades de toba (Carpio 2012; Censabella 2002; Manelis Klein 1978; Messineo 2003), también para la variedad del este de Formosa se observa que los pronombres demostrativos poseen una gran complejidad semántica y morfosintáctica, ya que en ellos se expresa: (i) la posición y la relación espacial, entre el hablante y la entidad referida por el nombre al que sustituyen en la frase nominal, (ii) los valores de género, cuando ocurren en singular y (iii) los valores de número. En esta variedad, a diferencia de las ya descritas, nuestro análisis plantea divergencias respecto a la distinción entre pronombres personales y pronombres demostrativos que, estimamos, no es aplicable en esta lengua. En González (2015: 47) había planteado: (i) la imposibilidad de distinguir entre pronombres personales de tercera persona y pronombres demostrativos, lo cual nos lleva a colocar en esta última categoría unidades que previamente han sido consideradas dentro de la primera (pronombres demostrativos que recurren a la combinación de una raíz deíctica con los sufijos -maze y -maGa) y (ii) la descripción de unidades que no se utilizan, de acuerdo a las gramáticas existentes, en las variedades chaqueñas. En los cuadros $1,2,3$ y 4 presentamos los paradigmas de pronombres demostrativos identificados:

\begin{tabular}{|c|c|c|c|}
\hline \multicolumn{2}{|c|}{ Paradigma -ma?e } & \multicolumn{2}{|c|}{ Paradigma -ma?a } \\
\hline \multicolumn{2}{|c|}{ Singular } & \multicolumn{2}{|c|}{ Singular } \\
\hline Masculino & Femenino & Masculino & Femenino \\
\hline $\begin{array}{l}\text { dama?e } \\
\text { ñima?e } \\
\text { yema?e } \\
\text { nama?e } \\
\text { soma?e } \\
\text { kama?e }\end{array}$ & $\begin{array}{l}\text { ha-dama?e } \\
\text { ha-ñima?e } \\
\text { ha-yema?e } \\
\text { ha-nama?e } \\
\text { ha-soma?e } \\
\text { ha-kama?e }\end{array}$ & $\begin{array}{l}\text { dama? a } \\
\text { ñima? a } \\
\text { Zema? a } \\
\text { nama? a } \\
\text { soma? a } \\
\text { kama?a }\end{array}$ & $\begin{array}{l}\text { ha-dama? a } \\
\text { ha-ñima? a } \\
\text { ha-?ema? a } \\
\text { ha-nama? a } \\
\text { ha-soma? a } \\
\text { ha-kama? a }\end{array}$ \\
\hline \multicolumn{2}{|c|}{ Plural } & \multicolumn{2}{|c|}{$\begin{array}{c}\text { Plural } \\
\end{array}$} \\
\hline \multicolumn{2}{|c|}{$\begin{array}{l}\text { da?ama?e } \\
\text { ñi?ima?e } \\
\text { ?e?ema?e } \\
\text { na?ama?e } \\
\text { so?oma?e } \\
\text { ka?ama?e }\end{array}$} & \multicolumn{2}{|c|}{$\begin{array}{c}\text { da?ama? a } \\
\text { ñi?ima? a } \\
\text { ?e?ema? a } \\
\text { na?ama? a } \\
\text { so?oma? a } \\
\text { ka?ama? a }\end{array}$} \\
\hline
\end{tabular}

Cuadro 1: Pronombres demostrativos con sufijos -maße y -maGa

En las descripciones de otras variedades de toba, tanto de Chaco (Censabella 2002, Manelis Klein 1978, Messineo 2003) como del oeste de Formosa (Carpio 2012), no se describe a las unidades que portan el sufijo maGa. Censabella (2002: 131), solamente menciona dos de las unidades de este paradigma, en su forma plural, so?omaGa y ka?amaGa las que define como formas poco utilizadas de pronombres personales con significado "ellos", y postula que podría tratarse de expresiones antiguas. En mocoví, lengua de la familia guaycurú, Gualdieri (1998: 188-189) describe formas pronominales construidas a partir de un morfema deíctico prefijado a un "morfema sufijal" y que dan como resultado PamaGare. 
Es decir, una forma casi idéntica a las halladas en toba del este. Estas formas con sufijo -maße y -maGa se especializan en el uso anafórico de referentes que revisten el rasgo [+HUMANo] dado que los referentes que son expresados por este paradigma son siempre humanos (4-5); o bien seres animados con rasgos humanizantes como el caso de animales mitológicos que son descritos en la cultura con valores o características propias de las personas.
(4) somaGa Ø-hek PDAL 3I-ir
'Él se fue'
(5) ha-damaGa d-asot-tak
F-PDPA 3I-bailar-PROG
'Ella está bailando'

\begin{tabular}{|c|c|c|c|}
\hline & \multicolumn{2}{|c|}{ Singular } & \multirow[t]{2}{*}{ Plural } \\
\hline & Masculino & Femenino & \\
\hline 'parado' & de?eda & $a-d a ? a d a$ & de?eda-wa \\
\hline 'sentado' & $\tilde{n} i ?$ ?ñ̃i & $a-\tilde{n} i ? i \tilde{n} i$ & $\tilde{n} i ? i \tilde{n} i-w a$ \\
\hline $\begin{array}{c}\text { 'acostado' } \\
\text { 'acercándose' }\end{array}$ & $\begin{array}{l}\text { ?e?e?e } \\
\text { ne?ena }\end{array}$ & $\begin{array}{l}\text { a-?e?e?e } \\
\text { a-na?ana }\end{array}$ & $\begin{array}{l}\text { ?e?e?e-wa } \\
\text { ne?ena-wa }\end{array}$ \\
\hline 'alejándose' & se?eso & a-sa?aso & se?eso-wa \\
\hline 'no-presente' & ke?eka & $a-k a ? a k a$ & ke?eka-wa \\
\hline
\end{tabular}

Cuadro 2: Formas duplicadas pronominales que codifican el rasgo [- animado]

En el caso de que estas formas se utilicen como pronombres, de manera anafórica, se expresa en ellos los mismos rasgos deícticos presentados previamente, codificados por medio de las raíces, y se distinguen de las unidades que agregan -maße y -maGa en que solamente pueden referir a nombres inanimados o bien a nombres abstractos o genéricos como en (6) y (7).

(6) sa-yamaqtaGaa-ñi de?eda

1I.PL-arreglar.1I.PL-AB PDPA

'Arreglamos eso

$\begin{array}{lll}\text { ma3e } & \text { qo-y-i-teg-a } & \text { qad-Paqtaqa } \\ \text { REL } & \text { P.IMP-3I-dice-PROG-AL } & \text { 1POSI.PL-idioma } \\ \text { que dicen nuestra lengua' } & \end{array}$

$\begin{array}{lll}\text { (7) depeda } & q 0-y-i-t e g-a & I 1-i k y-a G a k \\ \text { PDPA } & \text { P.IMP-3I-decir-PROG-AL } & \text { 3POSI-camino-NOM }\end{array}$ 'Eso que dicen el caminar' 
Los pronombres escuetos y su denominación se vinculan a que, comparados con las formas duplicadas, estas unidades son casi idénticas formalmente a las raíces deícticas.

Es un paradigma que cumple esencialmente funciones pronominales y que poseen rasgos morfosintácticos, semánticos y usos pragmáticos que lo diferencian de los dos paradigmas pronominales anteriores.

\begin{tabular}{|c|c|c|}
\cline { 2 - 3 } \multicolumn{1}{c|}{} & \multicolumn{2}{c|}{ Pronombres demostrativos escuetos } \\
\cline { 2 - 3 } \multicolumn{1}{c|}{} & Masculino & Femenino \\
\hline 'parado' & ?eda & ?ada \\
\hline 'sentado' & ?ñ̃i & ?añi \\
\hline 'acostado' & ?e?e & ?a?e \\
\hline 'acercándose' & ?ena & ?ana \\
\hline 'alejándose' & ?eso & ?aso \\
\hline 'no-presente' & ?eka & ?aka \\
\hline
\end{tabular}

Cuadro 3: Pronombres demostrativos escuetos

Se trata de unidades en las cuales no se codifica número (aunque en elicitación, ocasionalmente, puedan aparecer junto al sufijo pluralizador -wa), sino solamente género ya que conservan la marca de femenino a través de la infijación de -a- entre la oclusiva glotal y la raíz deíctica.

En términos semántico-pragmáticos pueden correferenciar y sustituir a un nombre no presente y desconocido, por ejemplo, en el caso de cláusulas no verbales interrogativas como en (8), donde el referente no solo no está presente, sino que no es recordado por el hablante.

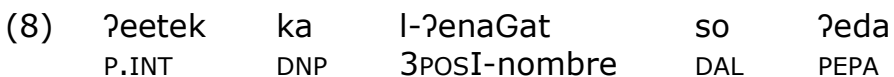
'¿Cómo era su nombre de aquél?'

En muchos casos las unidades de este paradigma se utilizan de modo enfático, para referir a un nombre previamente determinado por las raíces deícticas o las formas duplicadas como se muestra en (9) y (10).

(9) qa-i-waGan sepeso l-awak Peso P.IMP-3I-golpear DDAL 3POSI-agujero PEAL

'Golpean ese agujero, ese'

(10) wopo sepeso hawak peso EXIST DDAL agujero PEAL 'Hay este su agujero, este'

Existen, además, tres pronombres demostrativos que no han sido descritos para las variedades de Chaco, pero que sí son halladas por Carpio (2012: 63) en el toba de oeste y denominadas por esta autora "bases demostrativas exofóricas". 
Es decir que, de acuerdo con Diessel (1999: 94-95), se trata de unidades que refieren a entidades visibles o no visibles, respectivamente, ancladas en la situación de habla y que el hablante, a menudo, puede señalar con un gesto.

En nuestro corpus, a diferencia de los paradigmas previos, solo aparecen tres unidades, con distinción de género, sin codificación de número.

\begin{tabular}{|c|c|}
\hline Masculino & Femenino \\
\hline doho? & adoho? \\
\hline soho? & asoho? \\
\hline ñiho? & añiho? \\
\hline
\end{tabular}

Cuadro 4: Pronombres demostrativos con sufijo -ho?

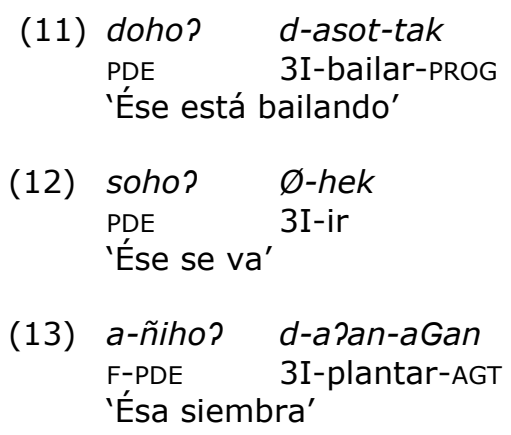

Resulta evidente, como ya planteamos en González (2015) que en toba estamos ante un complejo sistema de pronombres demostrativos, en el cual priman las indicaciones deícticas de diversa índole. Todo lo cual configura una confluencia que impide distinguir, desde nuestra perspectiva de análisis, entre pronombres personales de tercera persona y demostrativos. Dentro de estos últimos existen varias categorías, especializadas en distintas funciones que resumimos a continuación:

(i) Pronombres demostrativos que refieren a entes humanos o animados. Los mismos se componen de las raíces deícticas más los sufijos -maße y maGa.

(ii) Pronombres demostrativos que denotan entidades no humanas o inanimadas (pronombres duplicados). Comprenden las unidades de?eda/ada?ada, ñi?iñi/añipiñi, 3e?eze/aße?eze, ne?ena/ana?ana, se?eso/asa?aso, ke?eka/aka?aka.

(iii) Pronombres escuetos que codifican referentes no presentes en el acto de habla o que el hablante no puede identificar. En estos pronombres no se codifica número del referente: Peda/Pada, Piñi/Pañi, Peße/Paße, Pena/Pana, Peso/Paso, Peka/Paka.

(iv) Pronombres demostrativos exofóricos, con sufijo -ho? anclados a la situación de habla y que denotan entidades que pueden ser señaladas o apuntadas por el hablante. En comparación con los otros paradigmas, hemos hallado sólo tres unidades: doho?/adoho?, soho?/asoho?, ñiho?/añiho?. 


\section{Redefiniendo categorías}

Más allá de lo expuesto previamente, respecto a la imposibilidad de distinguir entre pronombres personales y pronombres de tercera persona, deseamos postular, siguiendo a Cysouw (1997), la inexistencia de la tercera persona en toba.

Como hemos presentado en González (2016), en toba oriental de Formosa no se observa una distinción inclusivo/exclusivo sino más bien una codificación diferencial de la primera persona plural.

De acuerdo con este patrón, la oposición se da entre las categorías de grupo/grupo restringido, lo cual evidencia, igualmente, una codificación diferencial de "nosotros". Este rasgo constituye un primer punto que pone en tensión la universalidad de la tercera persona, ya que añade distinciones semánticas en lo que tradicionalmente se denomina "primera persona plural" o no singular.

Una característica muy frecuente de diversas gramáticas, sobre todo de lenguas que ponen en tensión la tercera persona como categoría y se producen traslapes con los paradigmas demostrativos, es la presentación del paradigma de pronombres personales con el casillero vacío para la tercera. Esta forma de presentar los datos, si bien tiende a problematizar la universalidad de la tercera persona, asume su existencia como un a priori del cual debemos dar cuenta, incluso si nos obligamos a decir que existen formas demostrativas que "ocupan" ese casillero vacío.

Como ejemplo, eso fue exactamente lo que propuse en González (2015: 83), como se muestra en el cuadro 5.

\begin{tabular}{|c|c|c|}
\hline Persona & \multicolumn{2}{|c|}{ Número } \\
\hline $\mathbf{1}$ & Singular & Plural \\
\hline $\mathbf{2}$ & hayim & qo?omi /qomi? \\
\hline \multicolumn{2}{|c|}{$\varnothing$ (ver pronombres demostrativos) } \\
\hline
\end{tabular}

Cuadro 5: Pronombres personales independientes

Es decir, la tercera persona existe, como en la mayoría de lenguas indoeuropeas, pero no se encuentra en esta lengua o variedad de lengua o, en su defecto, esta especie de "deformación de base" viene a ser solventada, al menos en parte, por los paradigmas de pronombres demostrativos. Volvemos al argumento circular que presentamos en la introducción.

Retornamos al planteo de Cysouw (1997: 8): una forma más eficaz de clasificar a las unidades referenciales es en base a la oposición entre subjetivo/intersubjetivo. Por eficaz nos referimos al hecho de que permite analizar datos lingüísticos de cualquier lengua, sin presuponer la existencia de categorías como "pronombres personales de tercera persona" o "pronombres demostrativos". Las formas subjetivas son aquellas cuya propiedad referencial depende del hablante, como aquellas que se encuentran en la mayoría de las lenguas del mundo y refieren a formas equivalentes, en español, a "yo" y "vos". 
Las intersubjetivas, por su parte, son aquellas formas que pueden ser utilizadas por todos los participantes en el acto de habla y que no dependen de quien, ocasionalmente, ocupe el rol de hablante o turno de habla.

Desde esta perspectiva todos los elementos que, en la tradición de lenguas indoeuropeas, por ejemplo, se definen como pronombres personales de tercera persona, son formas intersubjetivas ya que su referencialidad no depende de la perspectiva, la distancia, la posición, etc. del hablante u oyente.

Por este motivo, cuando en una conversación el hablante utiliza la forma "él" no implica que el oyente deba, por ello, recurrir a otro elemento diferente como ocurre con las formas de primera y segunda persona. Los tradicionalmente denominados "pronombres demostrativos" pueden tener ambos usos, para el español, como se muestra en (14 a-b) y (15a-b).

(14) a. Eso que estás usando (un vestido), es hermoso.

b. Gracias, compre este (el mismo vestido) ayer.

(15) a. Ese es un muy buen restaurante para almorzar. b. Te refieres a ese? (apuntando con el dedo).

Podría afirmarse, a primera vista, que las formas demostrativas son mayoritariamente subjetivas (con usos intersubjetivos restringidos como en 15, cuando la posición y distancia respecto al referente entre hablante y oyente son similares o confluyen), pero esto depende mucho de las características semántico-pragmáticas que los elementos demostrativos posean según la lengua en estudio.

Generalmente, la deixis se construye a partir de uno de los participantes en el acto de habla. A esta altura, lo que podemos confirmar es que, al igual que la categoría pronombre personal de tercera persona, las formas intersubjetivas tampoco son universales y pueden existir lenguas que posean solamente formas subjetivas.

Lo interesante de este planteo teórico es que, reorganizando los datos que presentamos previamente en toba, no solamente podemos salir del derrotero que nos constriñe a elegir entre pronombres personales/demostrativos sino que, además, podemos ordenar en distintas categorías de deixis subjetiva e intersubjetiva elementos que siempre fueron pensados dentro de la misma clasificación en estudios previos. Considerando que la deixis en toba es codificada por seis raíces que, además, se comportan como elementos adnoninales en la lengua, proponemos en el cuadro 6 el siguiente reordenamiento: 


\begin{tabular}{|c|c|c|c|}
\hline \multicolumn{4}{|c|}{ DEIXIS (+) SUBJETIVA } \\
\hline \multicolumn{2}{|c|}{ Número } & \multicolumn{2}{|c|}{ Género } \\
\hline $\mathbf{S}$ & $\mathbf{P}$ & $M$ & $F$ \\
\hline hayim & qo?omi/qomi? & \multirow{2}{*}{\multicolumn{2}{|c|}{ no se codifica }} \\
\hline ?am & qa?ami/qami? & & \\
\hline na- & \multirow{2}{*}{$\begin{array}{l}-?- \\
-w a \\
-p i\end{array}$} & \multirow{2}{*}{$\varnothing-$} & \multirow[b]{2}{*}{ ha- } \\
\hline so- & & & \\
\hline \multicolumn{4}{|c|}{ DEIXIS ( +) INTERSUBJETIVA } \\
\hline \multicolumn{2}{|c|}{ Número } & \multicolumn{2}{|c|}{ Género } \\
\hline $\mathbf{S}$ & $\mathbf{P}$ & $\mathbf{M}$ & $\mathbf{F}$ \\
\hline da- & \multirow{4}{*}{$\begin{array}{l}-?- \\
-w a \\
-p i\end{array}$} & \multirow{4}{*}{$\varnothing-$} & \multirow{4}{*}{ ha- } \\
\hline$\tilde{n} i-$ & & & \\
\hline ?e- & & & \\
\hline ka- & & & \\
\hline
\end{tabular}

Cuadro 6: Deixis subjetiva e intersubjetiva en toba

Como puede observarse, estamos pensando más bien en la deixis subjetiva e intersubjetiva como continuums y no como oposiciones discretas. Por tal motivo, ubicamos a las unidades en los polos a los que más se acercan. Además, excluimos la categoría "persona" a los fines expositivos, dejando como único factor de ordenamiento la oposición subjetivo/intersubjetivo.

\section{Conclusiones}

A modo de cierre, resumimos lo expuesto. Estimamos que el reordenamiento, en torno a la deixis subjetiva e intersubjetiva, posee algunas ventajas respecto a la tradicional oposición entre pronombres personales de tercera persona y pronombres demostrativos:

- Podemos pensar más allá de la problemática definición del "pronombre" como categoría lingüística.

- No establece una definición de tercera persona como categoría negativa, a la vez que permite avanzar más bien hacia una noción positiva: deixis intersubjetiva, es decir, que puede ser utilizada por cualquiera de los participantes en el acto de habla.

- No obliga a presuponer la existencia de la tercera persona y, por ende, su codificación "cero" cuando no se observan elementos equivalentes a los tradicionales pronombres de tercera persona en las lenguas indoeuropeas, 0 cualquier lengua que distinga solamente tres personas gramaticales.

- No nos vemos forzado a adaptar nuestros datos a modelos pensados para otras lenguas, con lo cual, en términos translingüísticos, nos brinda un potencial comparativo mucho mayor. 
En términos prácticos y metodológicos, concebir estas dos categorías puede no ser de gran utilidad, sin embargo es válido para pensar en términos teóricos acerca de la evolución y desarrollo de las lenguas humanas así como aspectos vinculados a las necesidades comunicativas de los hablantes. Si bien las formas comúnmente llamadas demostrativos están más cercanas al polo de la deixis subjetiva, en muchas lenguas y ante la ausencia de formas intersubjetivas absolutas, pueden utilizarse intersubjetivamente de manera ocasional cuando los participantes en el acto de habla enuncian desde una ubicación temporo-espacial similar. De acuerdo con Cysouw (1997: 11), este rasgo de algunos demostrativos, el poder ser utilizados intersubjetivamente, puede explicar distintos procesos de gramaticalización que los involucran, ya que conduce a una ampliación de contextos de uso de los mismos.

En nuestra propuesta de reorganización en toba hemos colocado a los deícticos direccionales como deixis propiamente subjetiva (además de los pronombres de primera y segunda persona) y la forma que codifica a un referente ausente como netamente intersubjetiva. Los llamados "posicionales", que codifican la posición del referente, están más cerca de lo intersubjetivo ya que existe acuerdo en que determinados referentes se ubican en una posición específica (los árboles parados, los muertos acostados, etc.), no obstante, la extensión metafórica de estos usos básicos (que los acerca más a los usos subjetivos) conducen a que no podamos sostener que se trata de formas intersubjetivas plenas sino que desde una perspectiva escalar están más próximos a la intersubjetividad.

Este tipo de perspectiva nos permite romper con la noción de "lenguas exóticas" o "raras", para aquellas que no encajan en categorías esbozadas previamente para lenguas con siglos de tradición escrita. Al mismo tiempo, nos proporciona marcos analíticos para aproximarnos a los datos de cualquier lengua y poder analizarlos sobre una base común.

\section{Lista de fonemas y grafemas}

Consonánticos: $\mathrm{m}=$ labial nasal; $\mathrm{p}=$ labial oclusivo; $\mathrm{n}=$ alveolar nasal; $\mathrm{t}=$ alveolar

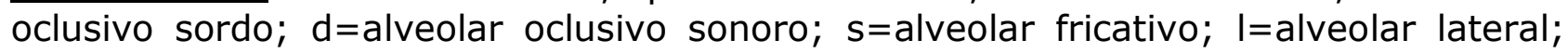
sh=postalveolar fricativo sordo; $3=$ postalveolar fricativo sonoro; $\tilde{n}=$ palatal nasal; $\mathrm{ch}=$ palatal oclusivo; $\|$ =palatal lateral; $\mathrm{y}=$ palatal aproximante; $\mathrm{k}=$ velar oclusivo sordo; $\mathrm{g}=$ velar oclusivo sonoro; $\mathrm{w}=\mathrm{velar}$ aproximante; $\mathrm{q}=\mathrm{uvular}$ oclusivo sordo; $\mathrm{G}=u \mathrm{vular}$ oclusivo sonoro; $?=$ glotal oclusivo; $\mathrm{h}=$ glotal fricativo.

Vocálicos: $a=$ posterior abierto; $\mathrm{e}=$ anterior abierto; $\mathrm{i}=$ anterior cerrado; $\mathrm{o}=$ posterior cerrado.

\section{Abreviaturas}

1I, 3I=índice pronominal primera y tercera persona paradigma 1; 1POSI, 3POSI=posesivo primera y tercera persona paradigma 1; AB=direccional 'abajo'; $\mathrm{AGT}=$ afijo 'agentivo'; $\mathrm{AL}=$ aplicativo 'alativo'; $\mathrm{DAL}=$ demostrativo adnominal 'alejamiento'; DDAL=demostrativo duplicado 'alejamiento'; DNP=demostrativo adnominal 'no presente'; EXIST=presentativo existencial; $F=$ femenino; $\mathrm{NOM}_{3}=$ nominalizador deverbativo 'actividad frecuente'; PDAL=pronombre demostrativo 'alejándose'; $\mathrm{PDE}=$ pronombre demostrativo exofórico; $\mathrm{PDPA}=$ pronombre duplicado 'parado'; PEAL= pronombre escueto 'alejamiento'; PEPA= pronombre escueto 'parado'; P.IMP=pasiva impersonal; P.INT=pronombre interrogativo; $\mathrm{PL}=$ plural; $\mathrm{PROG}=$ progresivo; REL=relativizador 


\section{Referencias bibliográficas}

Carpio, María Belén. 2007. Número y categorías afines en la lengua toba (familia Guaycurú, Argentina), en A. Fernández Garay y Marisa Malvestiti (eds.), Estudios Lingüísticos y sociolingüísticos de lenguas indígenas sudamericanas, Santa Rosa, Universidad Nacional de La Pampa: 13-27.

Carpio, María Belén. 2012. Fonología y morfosintaxis de la lengua hablada por grupos tobas en el oeste de Formosa (Argentina). München, LINCOM Europa Academic Publishers.

Censabella, Marisa. 2002. Descripción funcional de un corpus en lengua toba (familia Guaycurú, Argentina). Sistema fonológico, clases sintácticas y derivación. Aspectos de sincronía dinámica. Tesis de Doctorado, Universidad Nacional de Córdoba, Córdoba (Inédito).

Censabella, Marisa. 2007. Los aplicativos alativo y locativo en toba, en A. Fernández Garay, A. y M. Malvestiti (eds.) Estudios Lingüísticos y sociolingüísticos de lenguas indígenas sudamericanas. Santa Rosa, Universidad Nacional de La Pampa: 29-50.

Cysouw, Michael. 1997. 3rd Person Personal Pronoun: a Universal Category? [en línea] Disponible en http://cysouw.de/home/manuscripts_files/cysouwTIN97.pdf

Diessel, Holger. 1999. Demonstratives: form, function, and grammaticalization, Amsterdam/Philadelphia, John Benjamins Publishing Company.

Fabre, Alain. 2009. Los pueblos del Gran Chaco y sus lenguas, tercera parte: Los guaykurú. Suplemento Antropológico, 41, 2: 7-132.

González, Raúl Eduardo. 2010. Análisis sintáctico y semántico de dos aplicativos locativos en toba (familia guaycurú). Lingüística, 24: 123-140.

González, Raúl Eduardo. 2015. Estudio fonológico y morfosintáctico de la lengua toba hablada en el este de la provincia de Formosa (Argentina), München: LINCOM Europa Academic Publishers.

González, Raúl Eduardo. 2016. Codificación de las categorías de "grupo" y "grupo restringido" en toba del este de Formosa (Argentina), LIAMES 16, 2: 221-240.

Gualdieri, Beatriz. 1998. Mocovi (Guaicuru). Fonologia e morfossintaxe. Tesis de doctorado. Universidade Estadual Campinas, Campinas (Inédita).

INDEC. 2012. Censo Nacional De Población, Hogares y Viviendas, Serie B No 2, Buenos Aires, Instituto Nacional de Estadística y Censos.

Manelis Klein, Harriet E. 1978 Una gramática de la lengua toba: morfología verbal y nominal, Montevideo: Universidad de la República de la República.

Mendoza, Marcela y Pablo Wright. 1989. Sociocultural and economic elements of the adaptation systems of the Argentine Toba: the Nacilamolek and Taksek cases of Formosa Province, en S. Shennan (ed.), Archaeological approaches to cultural identity, London, Unwin Hyman: 242-257. 
Messineo, María Cristina. 2003. Lengua toba (guaycurú). Aspectos gramaticales y discursivos. München, LINCOM Europa Academic Publishers.

Miller, Elmer. 1979. Los tobas argentinos. Armonía y disonancia en una sociedad, México, Siglo Veintiuno Editores.

Siewierska, Ana. 2004. Person, Cambridge, Cambridge University Press.

Tola, Florencia. 2008. Constitución del cuerpo femenino entre los toba (qom) del este formoseño en S. Hirsch (coord.), Mujeres indígenas de la Argentina. Cuerpo, trabajo y poder, Buenos Aires, Biblos: 59-78.

Tovar, Antonio y Consuelo Larrucea de Tovar. 1984. Catálogo de las lenguas de América del sur, Madrid, Gredos.

Wright, Pablo. 2002. Ser católico y ser evangelio: tiempo, historia y existencia en la religión toba, ANTHROPOLÓGICAS, 13, 2: 61-81.

Wright, Pablo. 2008. Ser-en-el-sueño. Crónicas de historia y vida toba, Buenos Aires, Biblos.

NOTA:

El autor de este artículo es el único responsable por su contenido y redacción. 